\title{
A NEW APPROACH FOR THE PREDICTION OF TRAFFIC-INDUCED GROUND VIBRATION USING A HYBRID OPTIMIZED ANFIS-BASED MODEL
}

\author{
SAMO LUBEJ \& ANDREJ IVANIČ \\ Faculty of Civil Engineering, Transportation Engineering and Architecture, University of Maribor, Slovenia
}

\begin{abstract}
An attempt has been made to evaluate and predict the traffic-induced ground vibration using a hybrid optimized ANFIS-based model. Towards this aim, ground vibrations caused by traffic were monitored on a building located near the road. To investigate the appropriateness of this approach, the prediction by ANFIS was also compared with the most widely used vibration predictors. In this research, a hybrid of adaptive neuro-fuzzy inference system (ANFIS) optimized by particle swarm optimization (PSO) and genetic algorithm (GA) was proposed to predict traffic-produced ground vibration. The performance criterion selected for the comparison between the actual and the predicted data were the sum of squares due to error (SSE), the root mean square error (RMSE), and goodness of fit (R-square, adjusted R-square). It turns out that the hybrid GA-ANFIS prediction model outperforms the commonly used predictors and conventional ANFIS.
\end{abstract}

Keywords: ground vibration, adaptive neuro-fuzzy inference system, particle swarm optimization, genetic algorithm.

\section{INTRODUCTION}

Vibrations caused by traffic are a common concern of society, because they often cause problems for people as well as with buildings. The vibrations induced by traffic are transmitted through the pavement and then spread to the foundations of the building, which may be very annoying for its inhabitants. The most appropriate solution to given noise and vibrations problems require improvements or modification to the three basic elements:

- $\quad$ to modify the source of vibration (to reduce the noise or vibration output);

- to control the transmission path and the environment so as to reduce noise or vibration level reaching the recipient;

- $\quad$ to provide the receiver with a personal protective device.

Many earthworks, such as piling and vibration compaction of materials are causing vibrations, which may be transmitted through the ground to nearby facilities. These vibrations resulting in dynamic forces are having effects on objects and facilities in the immediate vicinity and are causing damage. In this case old buildings are most the vulnerable.

Traffic vibration is mainly caused by heavy vehicles, e.g. trucks and buses. Cars and light trucks rarely cause vibrations that are noticeable on buildings. Road transport is usually what causes vibration frequency in the range between 5 and $25 \mathrm{~Hz}$ and a speed variation of soil from 0.05 to $25 \mathrm{~mm} / \mathrm{s}$. The frequencies and the velocity of vibration depend on numerous factors, such as pavement conditions (especially damage and roughness), the speed and weight of vehicles, a vehicle suspension system, the type of soil, the season, the distance between the road and the building and the type of the building. There are two ways in which highway traffic can induce vibrations in nearby buildings:

- Ground-borne vibrations caused by dynamic impact forces of tires on the pavement surface that can propagate and excite footings and foundation walls below ground. 
Vibrations of footings and foundation walls can induce vibrations in other building components below or above ground.

- Air-borne vibrations caused by low frequency sound that can excite building components above ground. It should be noted that airborne vibration is not considered in this paper.

To predict traffic induced ground vibrations, several mathematical and empirical formulas were developed. These empirical equations often show great deviations between the calculated and measured peak particle velocity (PPV). Artificial neural network and neurofuzzy technique have better prediction capability then conventional vibration predictors [1]-[5]. In this paper, an attempt has been made to evaluate and predict the traffic-induced ground vibration by incorporating distance from the source of vibration to geophone, mass of vehicle, type of the speed bump and height of the speed by using an ANFIS.

\section{OPTIMIZATION METHODS}

ANFIS is the fuzzy inference system implemented in the framework of adaptive networks. The basic structure of the fuzzy inference system (FIS), which was introduced by Zadeh, comprises fuzzification of the input variables, application of the fuzzy operator (AND or OR) in the antecedent, implication from the antecedent to the consequent, aggregation of the consequents across the rules, and defuzzification. The most important reason for combining fuzzy systems with neural networks is to use learning capability of neural network. Such a combination should be able to learn linguistic rules and/or membership functions, or to optimize existing ones. The ANFIS architecture for two-rule two-input sugeno model is presented in Fig. 1.

\subsection{Genetic algorithm and Particle Swarm Optimization}

To optimize the ANFIS parameters of membership functions a Genetic algorithm (GA) and Particle Swarm Optimization (PSO) were utilized. Two main disadvantages of ANFIS are slow convergence and trapped in local minimum. The PSO is used for increasing convergence rate and avoidance of trapped in local minima. The PSO is used for increasing convergence rate and avoidance of trapping in local minima. In the recent past, various

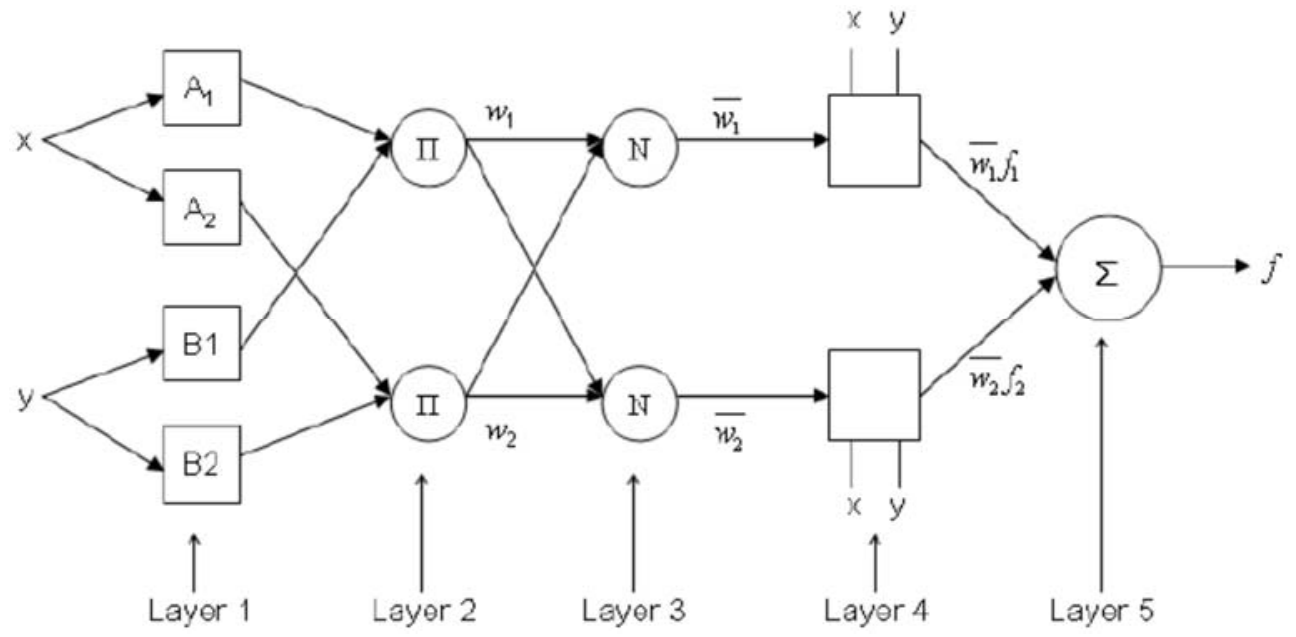

Figure 1: ANFIS architecture for two-rule two-input sugeno model. 
methods [6], [7] and algorithms have been applied to the optimization of structures [8]-[13]. However in this paper the optimization algorithms are used to obtain the best prediction model for traffic induced vibration.

\section{TRAFFIC-INDUCED GROUND VIBRATION PREDICTION}

\subsection{Data set}

The data was divided into training and testing datasets. Training datasets contain measurements of the vibration caused by trucks. In this case, data was collected using noisy measurements, therefore the training data cannot be representative of all the features of the data that will be presented in the model. For model validation we use testing data. In this model, 82 measurements from several sites were used. Among those, 57 evaluations $(70 \%)$ were used for the training of the ANFIS model, whereas 25 data sets $(30 \%)$ were chosen for checking the model. Tables 1 and 2 represent training and testing data. The frequencies and the velocity of vibration depend on numerous factors, such as pavement conditions (especially damage and roughness), the speed and weight of vehicles, a vehicle suspension system, the type of soil, the season, the distance between the road and the building and the type of the building.

The variables in the ANFIS model are:

- distance form source of vibration to geophone $d(\mathrm{~m})$;

- $\quad$ mass of vehicle $m$ (tons);

- $\quad$ type of the speed bump Type (1- trapezoid bump, 2- trapezoidal platform, 3- sinusoid bump);

- $\quad$ height of the speed bump $t(\mathrm{~cm})$.

The speed of the vehicle was $v=30 \mathrm{~km} / \mathrm{h}$ in all cases. The supporting soil type was silty clay which is very unlikely to settle when subjected to traffic induced vibration. It should be noted that all measurements were performed in the summer. Therefore, the seasonal variation of soil conditions is not considered on vibration levels. Moreover, the road was resurfaced before measuring the vibrations.

\subsection{Verification of the model for traffic-induced ground vibration prediction}

To test and validate the ANFIS models, a data set was selected that was not used during the training of the network. The ANFIS method is an alternative to existing methods for prediction of traffic-induced ground vibration. However, results need to be generalized as present work is valid only for considered data. Comparison of measured and predicted peak particle velocity PPV $(\mathrm{mm} / \mathrm{s})$ values for training data and testing data are shown in Figs 2 and 3, respectively. The objective function of the ANFIS model is to minimize the root mean square error (RMSE) between the measured and the predicted data. The performance criterion selected for the comparison between the measured and the predicted data is also the mean of squares due to error (MSE) and the standard deviation error. It turns out that the hybrid GA-ANFIS prediction model outperforms the commonly used predictors and conventional ANFIS. Therefore the results of GA are only presented in this paper. Table 3 show the comparison of GA-ANFIS model, PSO-ANFIS model and conventional-ANFIS model. 
Table 1: Training data.

\begin{tabular}{|c|c|c|c|c|c|c|c|c|c|}
\hline $\begin{array}{c}d \\
(\mathrm{~m})\end{array}$ & $\begin{array}{c}m \\
\text { (tons) }\end{array}$ & $\begin{array}{c}\text { Type } \\
(-)\end{array}$ & $\begin{array}{c}t \\
(\mathrm{~cm})\end{array}$ & $\begin{array}{c}\mathrm{PPV} \\
(\mathrm{mm} / \mathrm{s})\end{array}$ & $\begin{array}{c}d \\
(\mathrm{~m})\end{array}$ & $\begin{array}{c}m \\
\text { (tons) }\end{array}$ & $\begin{array}{c}\text { Type } \\
(-)\end{array}$ & $\begin{array}{c}t \\
(\mathrm{~cm})\end{array}$ & $\begin{array}{c}\mathrm{PPV} \\
(\mathrm{mm} / \mathrm{s})\end{array}$ \\
\hline 0.8 & 20 & 2 & 12 & 4.064 & 0.8 & 20 & 2 & 12 & 4.445 \\
\hline 2.5 & 12.5 & 3 & 6 & 0.254 & 0.5 & 12.5 & 3 & 6 & 6.477 \\
\hline 0.8 & 20 & 3 & 5 & 0.381 & 0.8 & 20 & 1 & 10 & 0.508 \\
\hline 8.4 & 20 & 1 & 10 & 0.254 & 0.8 & 20 & 1 & 10 & 0.508 \\
\hline 8.4 & 20 & 1 & 10 & 0.254 & 2 & 12.5 & 2 & 12 & 0.635 \\
\hline 2 & 12.5 & 2 & 12 & 0.508 & 0.8 & 20 & 3 & 5 & 0.381 \\
\hline 0.5 & 12.5 & 3 & 6 & 6.096 & 2 & 12.5 & 2 & 12 & 0.535 \\
\hline 1 & 12.5 & 3 & 6 & 3.048 & 8 & 20 & 3 & 5 & 0.254 \\
\hline 4.8 & 12.5 & 2 & 12 & 0.254 & 5.9 & 20 & 2 & 12 & 0.254 \\
\hline 4.8 & 12.5 & 2 & 12 & 0.254 & 5.9 & 20 & 2 & 12 & 0.254 \\
\hline 1 & 12.5 & 3 & 6 & 4.826 & 8.4 & 20 & 1 & 10 & 0.254 \\
\hline 0.8 & 20 & 2 & 12 & 4.826 & 5.9 & 20 & 2 & 12 & 0.254 \\
\hline 7.8 & 12.5 & 2 & 12 & 0.254 & 2.5 & 12.5 & 3 & 6 & 0.254 \\
\hline 0.8 & 20 & 1 & 10 & 0.254 & 3 & 12.5 & 3 & 6 & 0.127 \\
\hline 1 & 12.5 & 3 & 6 & 4.699 & 5 & 12.5 & 2 & 12 & 0.508 \\
\hline 8.4 & 20 & 1 & 10 & 0.254 & 5.9 & 20 & 2 & 12 & 0.254 \\
\hline 3 & 12.5 & 3 & 6 & 0.254 & 2 & 12.5 & 2 & 12 & 0.508 \\
\hline 5 & 12.5 & 2 & 12 & 0.635 & 3 & 12.5 & 3 & 6 & 0.254 \\
\hline 7.8 & 12.5 & 2 & 12 & 0.254 & 7.8 & 12.5 & 2 & 12 & 0.254 \\
\hline 0.8 & 20 & 3 & 5 & 1.397 & 3 & 12.5 & 3 & 6 & 0.254 \\
\hline 5 & 12.5 & 2 & 12 & 0.508 & 8.4 & 20 & 1 & 10 & 0.127 \\
\hline 0.8 & 20 & 1 & 10 & 0.254 & 5 & 12.5 & 2 & 12 & 0.508 \\
\hline 0.8 & 20 & 2 & 12 & 4.191 & 0.8 & 20 & 3 & 5 & 1.27 \\
\hline 1 & 12.5 & 3 & 6 & 3.683 & 0.8 & 20 & 3 & 5 & 0.635 \\
\hline 0.8 & 20 & 1 & 10 & 0.254 & 0.8 & 20 & 1 & 10 & 0.381 \\
\hline 5.9 & 20 & 2 & 12 & 0.254 & 4.8 & 12.5 & 2 & 12 & 0.172 \\
\hline 4.8 & 12.5 & 2 & 12 & 0.254 & 8 & 20 & 3 & 5 & 0.254 \\
\hline \multirow[t]{2}{*}{0.8} & 20 & 2 & 12 & 2.921 & 8.4 & 20 & 1 & 10 & 0.254 \\
\hline & & & & & 1 & 12.5 & 3 & 6 & 3.683 \\
\hline
\end{tabular}


Table 2: Testing data.

\begin{tabular}{|c|c|c|c|c|c|c|c|c|c|}
\hline $\begin{array}{c}d \\
(\mathrm{~m})\end{array}$ & $\begin{array}{c}m \\
(\text { tons })\end{array}$ & $\begin{array}{c}\text { Type } \\
(-)\end{array}$ & $\begin{array}{c}t \\
(\mathrm{~cm})\end{array}$ & $\begin{array}{c}\text { PPV } \\
(\mathrm{mm} / \mathrm{s})\end{array}$ & $\begin{array}{c}d \\
(\mathrm{~m})\end{array}$ & $\begin{array}{c}m \\
(\text { tons })\end{array}$ & $\begin{array}{c}\text { Type } \\
(-)\end{array}$ & $\begin{array}{c}t \\
(\mathrm{~cm})\end{array}$ & $\begin{array}{c}\text { PPV } \\
(\mathrm{mm} / \mathrm{s})\end{array}$ \\
\hline 0.8 & 20 & 2 & 12 & 3.302 & 0.8 & 20 & 2 & 12 & 3.81 \\
\hline 0.8 & 20 & 1 & 10 & 0.254 & 5.9 & 20 & 2 & 12 & 0.254 \\
\hline 3 & 12.5 & 3 & 6 & 0.254 & 5.9 & 20 & 2 & 12 & 0.254 \\
\hline 0.8 & 20 & 3 & 5 & 1.524 & 3 & 12.5 & 3 & 6 & 0.254 \\
\hline 1 & 12.5 & 3 & 6 & 4.826 & 8.4 & 20 & 1 & 10 & 0.254 \\
\hline 8 & 20 & 3 & 5 & 0.254 & 3 & 12.5 & 3 & 6 & 0.254 \\
\hline 8.4 & 20 & 1 & 10 & 0.254 & 8.4 & 20 & 1 & 10 & 0.254 \\
\hline 8 & 20 & 3 & 5 & 0.254 & 8 & 20 & 3 & 5 & 0.254 \\
\hline 0.8 & 20 & 1 & 10 & 0.254 & 7.8 & 12.5 & 2 & 12 & 0.254 \\
\hline 0.8 & 20 & 1 & 10 & 0.254 & 1 & 12.5 & 3 & 6 & 3.429 \\
\hline 1 & 12.5 & 3 & 6 & 4.445 & 7.8 & 12.5 & 2 & 12 & 0.254 \\
\hline 5 & 12.5 & 2 & 12 & 0.653 & 8 & 20 & 3 & 5 & 0.254 \\
\hline & & & & & 3 & 12.5 & 3 & 6 & 0.254 \\
\hline
\end{tabular}

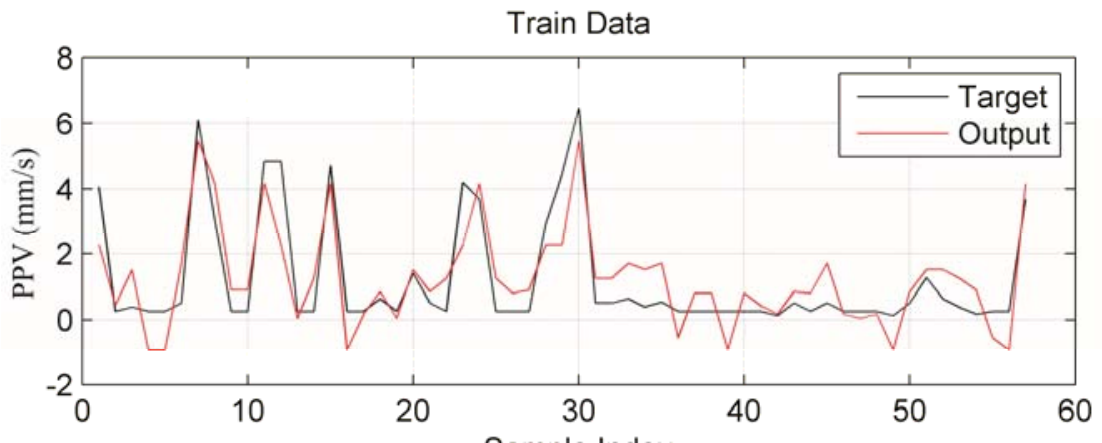

MSE $=0.86986$, RMSE $=0.93266$ Error Mean $=-0.019581$, Error St.D. $=0.94074$
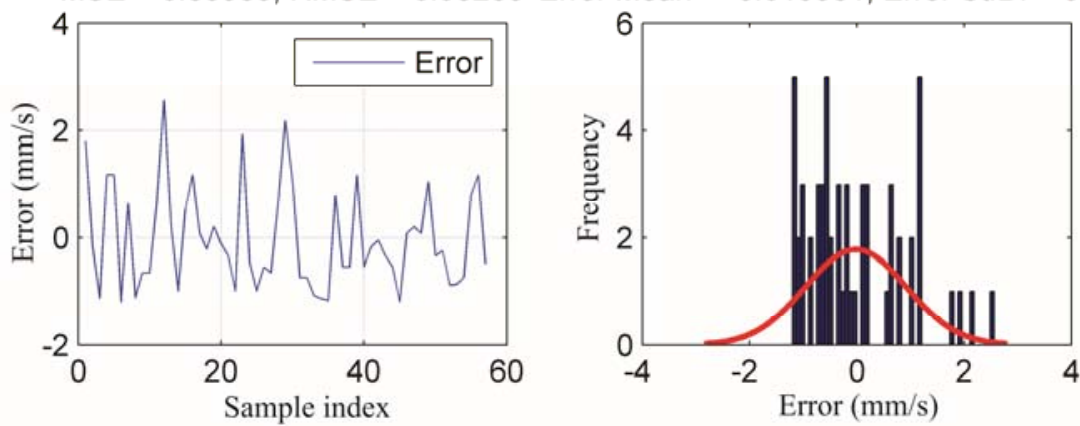

Figure 2: Comparison of measured and predicted PPV ( $\mathrm{mm} / \mathrm{s})$ values for training data. 

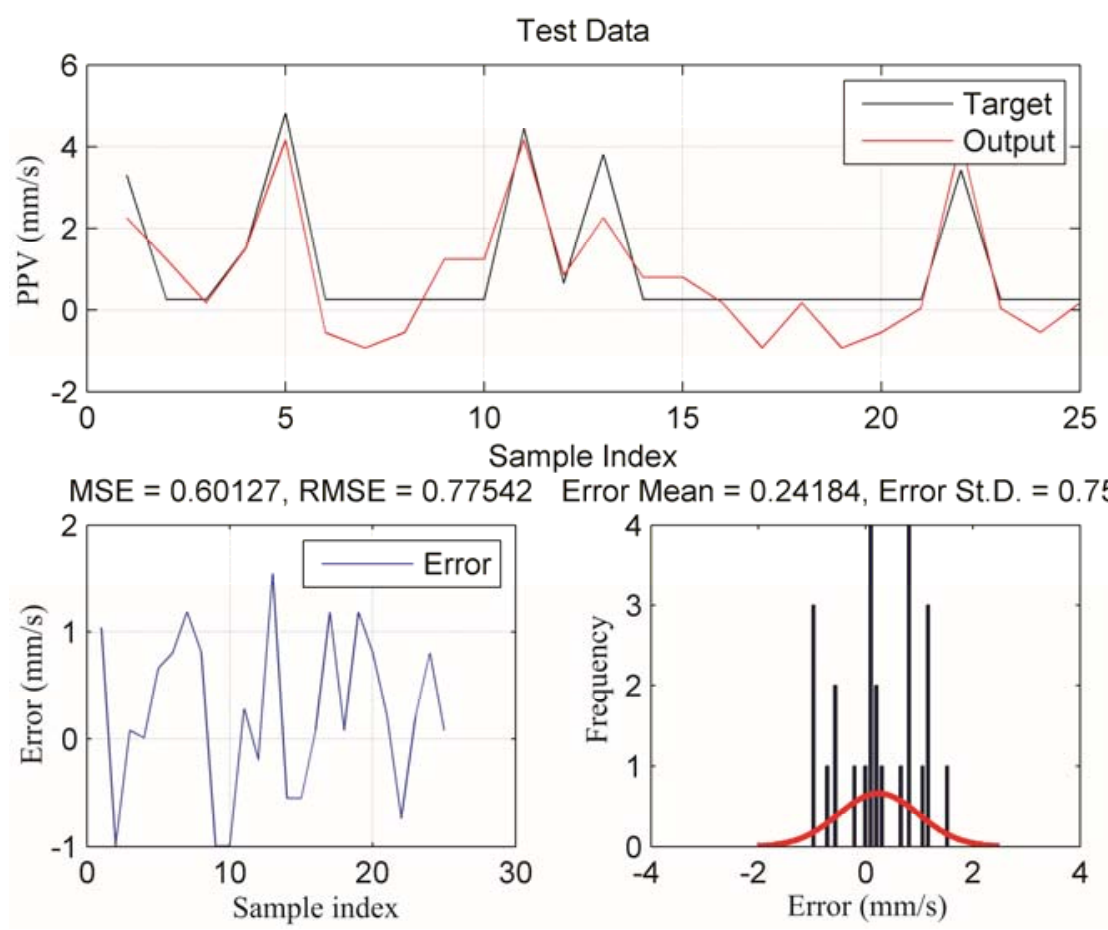

Figure 3: Comparison of measured and predicted PPV $(\mathrm{mm} / \mathrm{s})$ values for testing data.

Table 3: Comparison of GA-ANFIS model, PSO-ANFIS model and in terms of goodness of fit.

\begin{tabular}{|l|c|c|c|}
\hline Training & MSE & RMSE & Error St. D. \\
\hline GA-ANFIS & 0.86986 & 0.93266 & 0.94074 \\
\hline PSO-ANFIS & 1.6401 & 1.2807 & 1.2921 \\
\hline Conventional-ANFIS & 1.0766 & 1.0376 & 1.0468 \\
\hline Testing & MSE & RMSE & Error St. D. \\
\hline GA-ANFIS & 0.60127 & 0.77542 & 0.75194 \\
\hline PSO-ANFIS & 2.2993 & 1.5164 & 1.5442 \\
\hline Conventional-ANFIS & 0.9339 & 0.9664 & 0.9854 \\
\hline
\end{tabular}

\section{CONCLUSION}

Traffic induced vibrations under the described conditions were significantly lower than the most stringent guide value for heritage structure damage specified by existing standards. We found that this calculation provides a good estimate for predicting vibrations caused by heavy vehicle traffic. An artificial neural network and the neuro-fuzzy technique were used for modelling the ground vibration. The accuracy of the presented model could be improved with more measurements. It is found that an artificial neural network and the neuro-fuzzy technique have better prediction capability than a conventional peak particle velocity predictor. 


\section{REFERENCES}

[1] Jelusic, P., Soil compaction optimization with soft constrain. Journal of Intelligent and Fuzzy Systems, 29(2), pp. 955-962, 2015. DOI: 10.3233/IFS-151624.

[2] Žlender, B. \& Jelušič, P., Predicting geotechnical investigation using the knowledge based system. Advances in Fuzzy System., 2016. DOI: 10.1155/2016/4867498.

[3] Jelušič, P. \& Žlender, B., An adaptive network fuzzy inference system approach for site investigation. Geotechnical Testing Journal, 37(3), pp. 400-411, 2014. DOI: 10.1520/GTJ20120018.

[4] Žlender, B., Jelušič, P. \& Boumezerane, D., Planning geotechnical investigation using ANFIS. Geotechnical and Geological Engineering, 30(4), pp. 975-989, 2012. DOI: 10.1007/s10706-012-9520-7.

[5] Jelušič, P. \& Žlender, B., Soil-nail wall stability analysis using ANFIS. Acta Geotechnica Slovenica, 10(1), pp. 61-73, 2013.

[6] Jelušič, P. \& Žlender, B., Discrete optimization with fuzzy constraints. Symmetry (Basel), 9(6), pp. 1-22, 2017. DOI: 10.3390/sym9060087.

[7] Jelušič, P., Žlender, B. \& Dolinar, B., NLP optimization model as a failure mechanism for geosynthetic reinforced slopes subjected to pore-water pressure. International Journal of Geomechanics, 16(5), pp. 1-6, 2016. DOI: 10.1061/(ASCE)GM.19435622.0000604.

[8] Kravanja, S., Žula, T. \& Klanšek, U., Multi-parametric MINLP optimization study of a composite I beam floor system. Engineering Structures, 130, pp. 316-335, 2017. DOI: 10.1016/j.engstruct.2016.09.012.

[9] Jelusic, P. \& Kravanja, S., Optimal design of timber-concrete composite floors based on the multi-parametric MINLP optimization. Composite Structures, 179, pp. 285293, 2017. DOI: 10.1016/j.compstruct.2017.07.062.

[10] Kravanja, S., Turkalj, G., Šilih, S. \& Žula, T., Optimal design of single-story steel building structures based on parametric MINLP optimization. Journal of Constructional Steel Research, 81, pp. 86-103, 2013. DOI: 10.1016/ j.jcsr.2012.11.008.

[11] Jelušič, P. \& Žlender, B., Optimal design of piled embankments with basal reinforcement. Geosynthetics International, pp. 1-30, 2017. DOI: 10.1680/ jgein.17.00039.

[12] Žlender, B., Jelušič, P. \& Boumezerane, D., The feasibility analysis of underground gas storage caverns. Engineering Structures, 55, pp. 16-25, 2013. DOI: 10.1016/ j.engstruct.2013.01.003.

[13] Jelušič, P. \& Žlender, B., Optimal design of pad footing based on MINLP optimization. Soils and Foundations, 2018. DOI: 10.1016/J.SANDF.2018.02.002. 